CASE REPORT

\title{
A Clinical Case Study of Synchronous Breast Cancer
}

Mihai MEHEDINTU-IONESCUำ, Stefan-Andrei COMAN , Horia-Alexandru TOADER

\begin{abstract}
The following article represents a clinical case study of a synchronous breast cancer in a 47 year old woman with no prior significant comorbidities. Up to $10 \%$ of all breast cancers can be synchronous (usually found with the help of breast MRI). The occurrence of bilaterally is considerable with invasive lobular carcinoma. The patient observed after self-palpating her breast a nodule in the infero-external quadrant of the right breast. During almost 4 months the patient underwent punch biopsy of the right breast, lumpectomy and finally double mastectomy with immediate reconstruction using Mentor implants and AMD. The histopathological result showed ductal carcinoma in situ in the right breast and lobular carcinoma in situ in both breasts. Postoperatively the patient is free of cancer, but under clinical and imagistic surveillance.
\end{abstract}

Keywords: breast, cancer, woman, carcinoma, lobular.

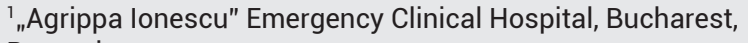
Romania

${ }^{2}$ "Carol Davila" University of Medicine and Pharmacy, Bucharest, Romania
Corresponding author:

Mihai MEHEDINTU-IONESCU, „Agrippa Ionescu” Emergency

Clinical Hospital, Bucharest, Romania.

E-mail:drmehedintu@gmail.com 


\section{BACKGROUND}

Second to skin cancer, breast cancer is the most common type of cancer in women. It is the second most important cause of cancer death after lung cancer. The incidence of breast cancer has decreased in the last decade due to the discontinuation of hormone replacement therapy in postmenopausal women ${ }^{1}$.

Up to $10 \%$ of all breast cancers can be synchronous (usually found with the help of breast MRI). The occurrence of bilaterally is considerable with invasive lobular carcinoma ${ }^{2,3}$.

The majority of women with breast cancer are eligible for breast reconstructive therapy after undergoing mastectomy, skin sparing(SSM) or nipple areola complex(NSM) sparring mastectomy and receiving some form of systemic or local adjuvant therapy, like radiotherapy or chemotherapy depending on the histological type of the tumor ${ }^{1,3,4}$.

The main reconstructive methods used in the authors clinic are autologous tissue reconstruction using DIEP flaps, latissimus dorsi flaps and alloplastic reconstruction using materials such as implants, tissue expanders and ADM.

\section{CASE PRESENTATION}

The following article represents a clinical case study of a synchronous breast cancer in a 47 year old woman with no prior significant comorbidities.

The patient observed after self-palpating her breast a nodule in the infero-external quadrant of the right breast.

Bloodwork just showed a high glucose level and hypercholesterolemia.

Local clinical examination revealed a nodule in the infero-external quadrant, oval shaped, size of $1.5 / 1 \mathrm{~cm}$, firm, detachable from the deep structures, painless, with no local adenophaties and time of appearance 4 months ago.

The patient had an MRI of the breast done in November 2020 with no concluding results.

In November 2020 she underwent a punch-biopsy under ultrasound guidance and 3 samples were taken.

The histopathological result showed breast tissue with adenosis, flat epithelial atypia and foci of ductal epithelial hyperplasia, typical and atypical.

The oncology committee recommended lumpectomy ${ }^{5}$.

The second step was in January 2021 when under general anesthesia she underwent lumpectomy with the excision of the axillary extension of breast tissue. There were no postoperative complications.

This time the histopathological findings showed sclerosing adenosis with outbreaks of ductal carcinoma in situ (DCIS), low nuclear grade, $\mathrm{pTispNx}$, ER (90\%) and PgR (70\%) positive and lobular carcinoma in situ(LCIS), classic, multifocal, present in the edge of excision. $^{6-9}$

The tumor board based on NCCN guidelines recommended bilateral skin sparing mastectomy and breast reconstruction ${ }^{5,10}$.

Based on her weight, risks, skin flaps, recommendations of the tumor board, her own choice the decision for bilateral skin-sparring mastectomy and dual plane breast reconstruction with Mentor implants and ADM, $280 \mathrm{CC}$ for the left breast and $330 \mathrm{CC}$ for the right breast was taken and the procedure took place 2 months after the decision because of COVID outbreak. The operation was successful with no postoperative complications ${ }^{11-23}$.

The histopathological result revealed right mammary gland with single outbreak of ductal carcinoma in intermediate nuclear site, architectural type cribriform, without necrosis; numerous disseminated outbreaks of lobular carcinoma in situ; multiple lesions of usual ductal hyperplasia, sclerosing adenosis, flat epithelial atypia and columnar cell changes, edges of excision free of carcinoma in situ.

Left mammary gland with multifocal lobular carcinoma in situ, disseminated lesions of usual ductal hyperplasia, sclerosing adenosis, flat epithelial atypia and columnar cell changes, excision edges free of carcinoma in situ ${ }^{6-9}$.

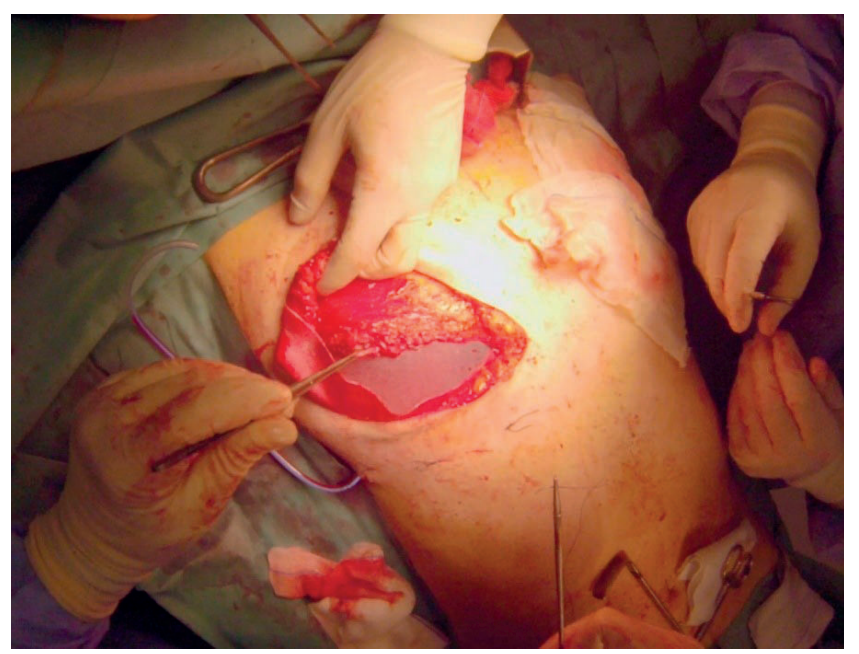



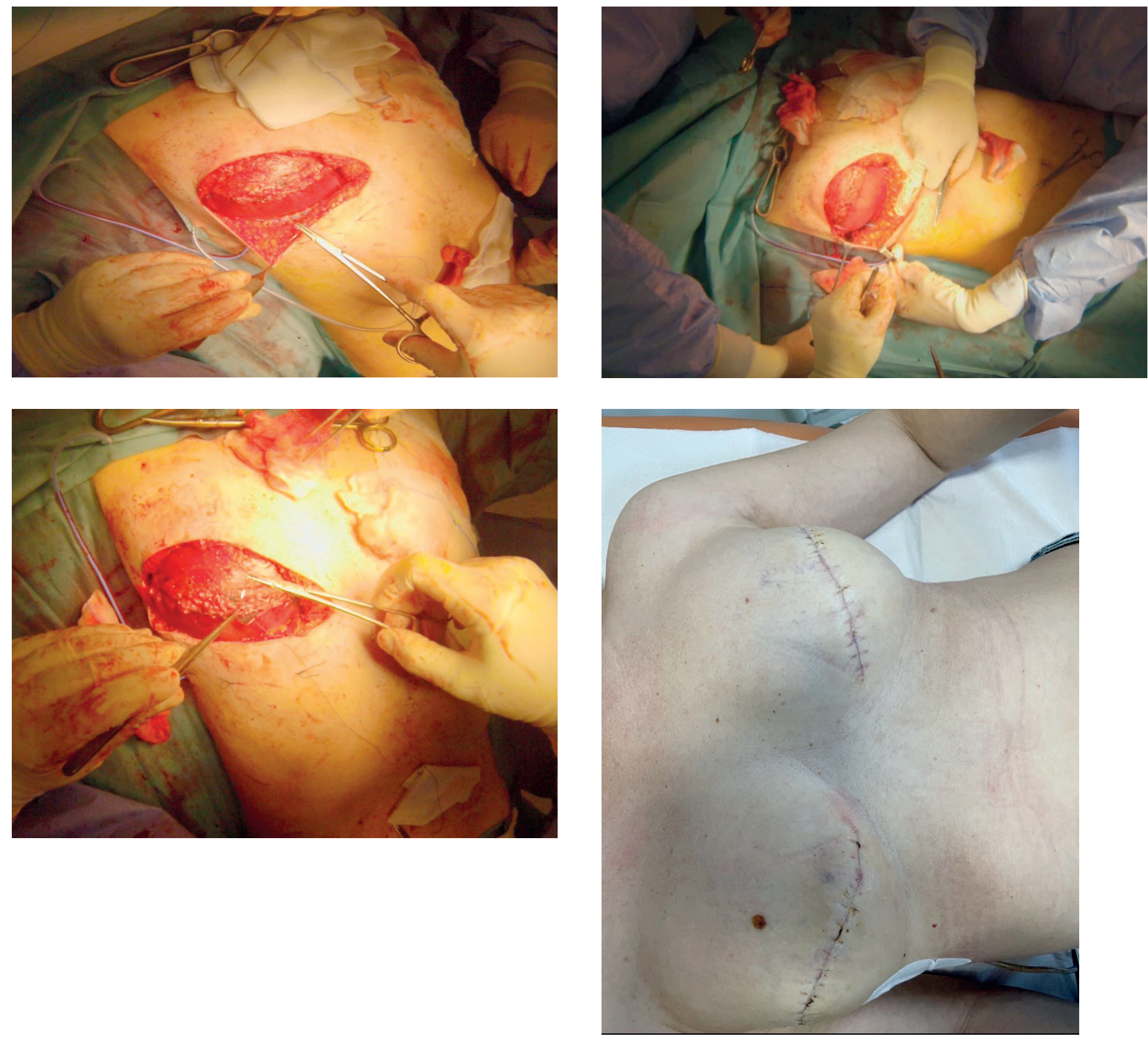

\section{CONCLUSIONS}

Postoperatively the patient is free of cancer, but under clinical and imagistic surveillance. She is scheduled to have the NAC reconstruction at 12 months.

The take-away message that emerges from this article is that although the imaging had not detected anything unusual and no mastectomy with bilateral reconstruction was recommended, the oncologist confirmed and approved the therapeutic solution of mastectomy with immediate reconstruction, because there was a percentage of probability that needed to be covered and the histopathological result confirmed the suspicion.

Compliance with ethics requirements: The authors declare no conflict of interest regarding this article. The authors declare that all the procedures and experiments of this study respect the ethical standards in the Helsinki Declaration of 1975, as revised in 2008(5), as well as the national law. Informed consent was obtained from all the patients included in the study. 


\section{References}

1. Grab and Smith's Plastic Surgery, seventh edition, ed. 2014 page 620

2. Synchronous breast cancer | Radiology Reference Article | Radiopaedia.org

3. van Verschuer VMT, Mureau MAM, Heemskerk-Gerritsen BAM, et al. Long-term outcomes of bilateral direct-to-implant breast reconstruction in women at high breast cancer risk. J Plast Surg Hand Surg. 2018;52(4):245-252.

4. Galimberti V, Vicini E, Corso G, et al. Nipple-sparing and skin-sparing mastectomy: Review of aims, oncological safety and contraindications. Breast. 2017;34 Suppl 1(Suppl 1):S82-S84.

5. https://www.nccn.org/professionals/physician_gls/pdf/ breast.pdf

6. Dossus L, Benusiglio PR. Lobular breast cancer: incidence and genetic and non-genetic risk factors. Breast Cancer Res. 2015;17:37. Published 2015 Mar 13.

7. Wen HY, Brogi E. Lobular Carcinoma In Situ. Surg Pathol Clin. 2018;11(1):123-145.

8. Cutuli B. Les carcinomes canalaires in situ en 2019 : diagnostic, traitement, pronostic [Ductal carcinoma in situ in 2019: Diagnosis, treatment, prognosis]. Presse Med. 2019;48(10):11121122.

9. Badve SS, Gökmen-Polar Y. Ductal carcinoma in situ of breast: update 2019. Pathology. 2019;51(6):563-569.

10. Pride RM, Jimenez RE, Hoskin TL, Degnim AC, Hieken TJ. Upgrade at excisional biopsy after a core needle biopsy diagnosis of classic lobular carcinoma in situ. Surgery. 2021;169(3):644648

11. Han HH, Kim HB, Kim EK, Eom JS. Direct-to-Implant as a Frontline Option for Immediate Breast Reconstruction: A Comparative Study With 2-Stage Reconstruction. Ann Plast Surg. 2018;81(3):274-279. doi:10.1097/SAP.0000000000001517

12. Hunsicker LM, Ashikari AY, Berry C, Koch RM, Salzberg CA. Short-Term Complications Associated With Acellular Dermal Matrix-Assisted Direct-to-Implant Breast Reconstruction. Ann Plast Surg. 2017;78(1):35-40.

13. Yang JY, Kim CW, Lee JW, Kim SK, Lee SA, Hwang E. Considerations for patient selection: Prepectoral versus subpectoral implant-based breast reconstruction. Arch Plast Surg. 2019;46(6):550-557.
14. Isaksson K, Arver B, Bottai M, Pettersson A, Wickman M, Sandelin K. Bilateral Risk-Reducing Mastectomies with Implant-Based Reconstructions Followed Long Term: A Consecutive Series of 185 Patients. World J Surg. 2019;43(9):2262-2270.

15. Nealon KP, Sobti N, Gadd M, Specht M, Liao EC. Assessing the additional surgical risk of contralateral prophylactic mastectomy and immediate breast implant reconstruction. Breast Cancer Res Treat. 2020;179(2):255-265.

16. Buendía J, Olivas-Menayo J. Improving Cost-efficiency in Bilateral Direct-to-Implant Reconstructions with Acellular Dermal Matrix. Plast Reconstr Surg Glob Open. 2019;7(9):e2447. Published 2019 Sep 30.

17. Ozturk CN, Ozturk C, Soucise A, et al. Bilateral immediate two-stage breast reconstruction in patients with unilateral breast cancer: Outcomes analysis and risk assessment. J Plast Reconstr Aesthet Surg. 2021;74(3):480-485

18. Brown $M$, Namnoum JD. Indications and Controversies for Implant-Only Based Breast Reconstruction. Clin Plast Surg. 2018;45(1):47-54

19. Albornoz CR, Matros E, Lee CN, et al. Bilateral Mastectomy versus Breast-Conserving Surgery for Early-Stage Breast Cancer: The Role of Breast Reconstruction. Plast Reconstr Surg. 2015;135(6):1518-1526

20. Disa JJ, Matros E. Discussion: Risk-to-Benefit Relationship of Contralateral Prophylactic Mastectomy: The Argument for Bilateral Mastectomies with Immediate Reconstruction. Plast Reconstr Surg. 2019;144(1):10-11

21. Bletsis P, Bucknor A, Chattha A, et al. Evaluation of Contralateral and Bilateral Prophylactic Mastectomy and Reconstruction Outcomes: Comparing Alloplastic and Autologous Reconstruction. Ann Plast Surg. 2018;80(4 Suppl 4):S144-S149.

22. Huang J, Wang M, Chagpar A. Factors Associated with Reconstruction in Patients Undergoing Mastectomy. Am Surg. 2020;86(2):134-139.

23. Alba B, Schultz BD, Cohen D, Qin AL, Chan W, Tanna N. Risk-to-Benefit Relationship of Contralateral Prophylactic Mastectomy: The Argument for Bilateral Mastectomies with Immediate Reconstruction. Plast Reconstr Surg. 2019;144(1):1-9. 